\title{
Effects of herbal Epimedium on the improvement of bone metabolic disorder through the induction of osteogenic differentiation from bone marrow-derived mesenchymal stem cells
}

\author{
DO RIM KIM, JI EUN LEE, KYUNG JUN SHIM, JIN HYOUNG CHO, \\ HO CHUL LEE, SEONG KYU PARK and MUN SEOG CHANG
}

Department of Prescriptionology, College of Korean Medicine, Kyung Hee University, Seoul 02447, Republic of Korea

Received November 4, 2015; Accepted November 3, 2016

DOI: $10.3892 / \mathrm{mmr} .2016 .6015$

\begin{abstract}
Herbal Epimedium (HE) has been commonly used as a tonic, antirheumatic agent and in the treatment of bone-associated diseases including osteoporosis. Treatment for osteoporosis is important to increase bone mass density and maintain to balance of bone remodeling. The present study was performed to investigate the effects of HE on mouse bone marrow mesenchymal stem cell (mBMMSC) proliferation and osteogenic differentiation, using MTT assays, proliferating cell nuclear antigen (PCNA) detection and apoptosis and differentiation assays. HE was demonstrated to inhibit the proliferation of mBMMSCs up to $45.43 \pm 3.33 \%$ and to decrease the level of PCNA expression compared with untreated cells. $\mathrm{HE}$ also induced late apoptosis at 24 and $48 \mathrm{~h}$ after treatment up to 71.93 and $67.03 \%$, respectively, while only $14.93 \%$ of untreated cells exhibited apoptosis. By contrast, HE induced differentiation of mBMMSCs into an osteogenic lineage at the beginning of three weeks after commencement of treatment. This suggested that HE is a candidate as an inducer of osteogenesis from bone marrow mesenchymal stem cells, and additionally has potential for use in the treatment of bone metabolic disorders such as osteoporosis.
\end{abstract}

\section{Introduction}

With an increase in the elderly population, the occurrence of bone-associated diseases including osteoporosis, osteoarthritic bone and joint disease will increase, and these diseases affect the quality of life of the patients affected (1). In particular, osteoporosis is a metabolic bone disorder

Correspondence to: Professor Mun Seog Chang, Department of Prescriptionology, College of Korean Medicine, Kyung Hee University, 26 Kyunghee Dae-ro, Dongdaemun-gu, Seoul 02447, Republic of Korea

E-mail: mschang@khu.ac.kr

Key words: Herbal Epimedium, osteogenic differentiation, mouse bone marrow mesenchymal stem cells, apoptosis, osteoporosis characterized by a reduction in bone density and an increase in the fracture risk, which may influence up to $50 \%$ women and $20 \%$ men over 50 years of age $(2,3)$. Bone remodeling occurs continuously throughout our lifetime and unbalance of bone remodeling is the cause of osteoporosis (4). Treatment for osteoporosis is focused on drug therapy using bone resorption inhibitors. Although this drug therapy aids in the prevention of osteoporosis, side effects are present, and there are limitations in the regeneration of bone tissue (5). Regenerative medicine with autologous transplantation such as embryonic stem cell, induced pluripotent stem cell and adult stem cell is an alternative method to repair bone loss of osteoporosis (6).

Mesenchymal stem cells (MSCs) are characterized by their ability to give rise to differentiated stromal cells, which belong to the osteogenic, chondrogenic, adipogenic, myogenic and fibroblastic lineages, and their capacity for self-renewal potential (7-9). MSCs maintain a balance between stem cell and differentiated cell populations by asymmetrical cell division (10). Their multipotency and self-renewal potential makes them attractive targets for cell and gene therapy, and the differentiation of MSCs into the osteogenic lineage is important for bone regeneration, as observed in osteogenesis imperfecta, which is caused by abnormal collagen production or hypophosphatasia, a disorder of osteoblasts and chondrocytes $(11,12)$. However, the application of gene and cell therapy methodologies to MSCs is limited by the reduced differentiation and proliferation potential of these cells in culture.

Herbal Epimedium (HE) is used as a tonic, aphrodisiac and antirheumatic in Korea, and consists of flavonoids, alkaloids, lignans and terpenic compounds. HE has been demonstrated to decrease the total cholesterol and triglyceride levels, however to increase estradiol (13), and flavonoid components of HE have been reported to have antioxidant properties (14). HE flavonoids stimulate osteoblast formation and suppress the process of osteoclastogenesis in ovariectomized mice, and thus prevent bone loss in this model (15). However, little is known about the effects of HE extract formula on the balance between proliferation and differentiation potential of mouse bone marrow MSCs (mBMMSCs). The present study aimed to identify the effects of $\mathrm{HE}$ on proliferation and differentiation 
potential of mBMMSCs using a series of experiments including viability assays, cell cycle analysis, immunohistochemistry and differentiation assays.

\section{Materials and methods}

mBMMSC culture. Mouse stromal cells were isolated according to a modification of the protocol of Nadri and Soleimani (16). A total of three C57BL/6 mice (male, 8-12 weeks of age; weight, 20-22 g; SLC Inc., Hamamatsu, Japan) were used. The animals were housed in a specific pathogen-free environment with 12/12 h light/dark cycles at the Center for Laboratory Animal Care and Use at Kyung Hee University (Seoul, Korea). Animals had free access to standard rodent pellets and water (Purine, Seoul, Korea). The mice were anesthetized by intraperitoneal injection of urethane $(100 \mathrm{mg} / \mathrm{kg}$; Sigma-Aldrich; Merck Millipore, Darmstadt, Germany). Bone marrow cells were obtained by flushing the femurs and tibias of the C57BL/6 mice with Dulbecco's Modified Eagle's medium (DMEM; Gibco; Thermo Fisher Scientific, Inc., Waltham, MA, USA) supplemented with $15 \%$ fetal bovine serum (FBS; Gibco; Thermo Fisher Scientific, Inc.), $100 \mathrm{U} / \mathrm{ml}$ penicillin and $100 \mathrm{mg} / \mathrm{ml}$ streptomycin. Single-cell suspensions were prepared from clumps of bone marrow by resuspending the cells using a syringe mounted with a 26 -gauge needle, and passing them through a $70-\mathrm{mm}$ cell strainer (Falcon; BD Biosciences, Heidelberg, Germany). The cells were cultured in DMEM with $15 \% \mathrm{FBS}, 100 \mathrm{U} / \mathrm{ml}$ penicillin and $100 \mathrm{mg} / \mathrm{ml}$ of streptomycin on $0.1 \%$ gelatin-coated $10-\mathrm{cm}$ dishes at $37^{\circ} \mathrm{C}$ in a humidified atmosphere of $5 \% \mathrm{CO}_{2}$.

Preparation of HE extract. HE was purchased from Wonkwang Herbal Drug Co., Ltd. (Seoul, Korea). Samples of $300 \mathrm{~g}$ of dried medicinal herbs were boiled in 61 of water for $2 \mathrm{~h}$ at $100^{\circ} \mathrm{C}$, and the suspensions were then filtered and evaporated under reduced pressure. The filtrates were lyophilized and yielded $37.1 \mathrm{~g}$ of powder. Dried extracts were dissolved in distilled deionized water (EMD Millipore, Billerica, MA, USA) and vortexed for $2 \mathrm{~min}$ at room temperature.

Liquid chromatography-tandem mass spectrometry ( $L C-M S / M S)$. Stock solution of reference standard, icarrin was prepared in DMSO at a concentration of $1 \mathrm{mg} / \mathrm{ml}$. The working solutions for MS analysis were prepared in $80 \%$ acetonitrile at concentration of $1000 \mathrm{ng} / \mathrm{ml}$. For each standard curve, six calibration standards (at 50, 100, 250, 500 and $1000 \mathrm{ng} / \mathrm{ml}$ ) were analyzed. For HE analysis, $10 \mathrm{mg} / \mathrm{ml} \mathrm{HE}$ was dissolved in $80 \%$ acetonitrile and was separated by centrifugation at $1,152 \times g$ for $10 \mathrm{~min}$ at $25^{\circ} \mathrm{C}$. The clear supernatant extract was filtered through $0.45-\mu \mathrm{m}$ membrane filter prior to LC-MS/MS determination.

Chromatography was performed on a liquid chromatography system (Agilent Technologies, Inc., Santa Clara, CA, USA). A $500 \mu \mathrm{l}$ aliquot of diluted HE was injected onto a 100x2.1 mm, Atlantis DC18 column (Waters Corporation, Milford, MA, USA). The column was maintained at $20^{\circ} \mathrm{C}$. Mobile phases A and B consisted of $0.1 \%$ aqueous formic acid and acetonitrile, respectively, and were eluted with a linear gradient of 5-95\% in $20 \mathrm{~min}$ at a flow rate of $0.2 \mathrm{ml} / \mathrm{min}$.
The QTRAP 3200 mass spectrometer system (Ab Sciex, Framingham, MA, USA) operated in positive ionization modes was used in the current study and processed with multiple reactions monitoring (MRM) scanning. The mobile phase contained acetonitrile in water with $0.1 \%(\mathrm{v} / \mathrm{v})$ formic acid. Under the optimized condition for positive mode, nitrogen was used as drying gas, $101 \mathrm{~min}-1$ and nebulizer gas, $50 \mathrm{psi}$, while the voltage of ion spray in source was set at $5500 \mathrm{~V}$ and the gas temperature was $400^{\circ} \mathrm{C}$.

Cell viability, proliferation, proliferating cell nuclear antigen (PCNA) detection and apoptosis assays. Cell proliferation was determined by MTT assay. mBMMSCs were starved for $24 \mathrm{~h}$ and then treated with the indicated concentrations of $\operatorname{HE}(1,10,50,75,100$ or $200 \mathrm{mg} / \mathrm{ml})$. After 12, 24 and $48 \mathrm{~h}$, the medium was removed and the cells were incubated with MTT to measure metabolic activity. For detection of PCNA, mBMMSCs in starvation medium were incubated with HE (100 ug/ml) basic fibroblast growth factor (bFGF; Gibco; Thermo Fisher Scientific, Inc.) and various inhibitors (SB202190 and PD98059; Cell Signaling Technology, Danvers, MA, USA) for $24 \mathrm{~h}$, before they were fixed and permeabilized in cold methanol, washed three times and blocked for $1 \mathrm{~h}$, at room temperature in DMEM-based buffer containing 5\% FBS. Samples were washed and incubated overnight with an anti-PCNA antibody (dilution, 1:200; cat. no. M0879; Dako; Agilent Technologies, Inc.) at $4^{\circ} \mathrm{C}$. The cells were then washed three times and incubated for $4 \mathrm{~h}$ with the goat anti-mouse Alexa 488 antibody (excitation $488 \mathrm{~nm}$, emission $519 \mathrm{~nm}$; dilution, 1:200; cat. no. A21202; Invitrogen; Thermo Fisher Scientific, Inc.). For detection of nuclei, cells were incubated for $5 \mathrm{~min}$ with propidium iodide (PI; $3.75 \mathrm{mg} / \mathrm{ml}$; excitation $540 \mathrm{~nm}$, emission $630 \mathrm{~nm}$ ). Apoptosis was evaluated using a commercial Annexin V/Fluorescein Isothiocyanate (FITC) Apoptosis detection kit (BD Biosciences, San Jose, CA, USA) on cells stained with annexin $\mathrm{V}$ according to the manufacturer's instructions. Cells positive for annexin $\mathrm{V}$ were counted by fluorescence-activated cell sorting and analyzed using CellQuest Pro software (version 5.1; BD Biosciences) to determine the percentage of cells undergoing early apoptosis and late apoptosis.

Bone marrow MSC differentiation assays. The potential of the isolated cells to differentiate into osteogenic and adipogenic lineages was examined. For osteogenesis, the cultured cells were incubated in osteogenic conditioned medium, as described previously by Eslaminejad and Nadri (17). Briefly, DMEM was supplemented with $10 \mathrm{mM} \beta$-glycerol phosphate (Sigma-Aldrich; Merck Millipore), $50 \mathrm{mg} / \mathrm{ml}$ ascorbate-2-phosphate (Sigma-Aldrich; Merck Millipore), and $10^{-7} \mathrm{M}$ dexamethasone (Sigma-Aldrich; Merck Millipore). The cells were fixed with methanol for $10 \mathrm{~min}$ at room temperature and stained with Alizarin red ( $\mathrm{pH} \mathrm{4.0)}$ for $5 \mathrm{~min}$ at room temperature and with Von Kossa staining for bone nodule formation. For adipogenesis, the cultured cells were incubated in adipogenic medium consisting of DMEM supplemented with $50 \mathrm{mg} / \mathrm{ml}$ indomethacin (Sigma-Aldrich; Merck Millipore), $10^{-7} \mathrm{M}$ dexamethasone, and $50 \mathrm{mg} / \mathrm{ml}$ ascorbate-2-phosphate. The cells were then fixed in methanol for $45 \mathrm{~min}$ and stained with Oil red O (Sigma-Aldrich; Merck Millipore). 

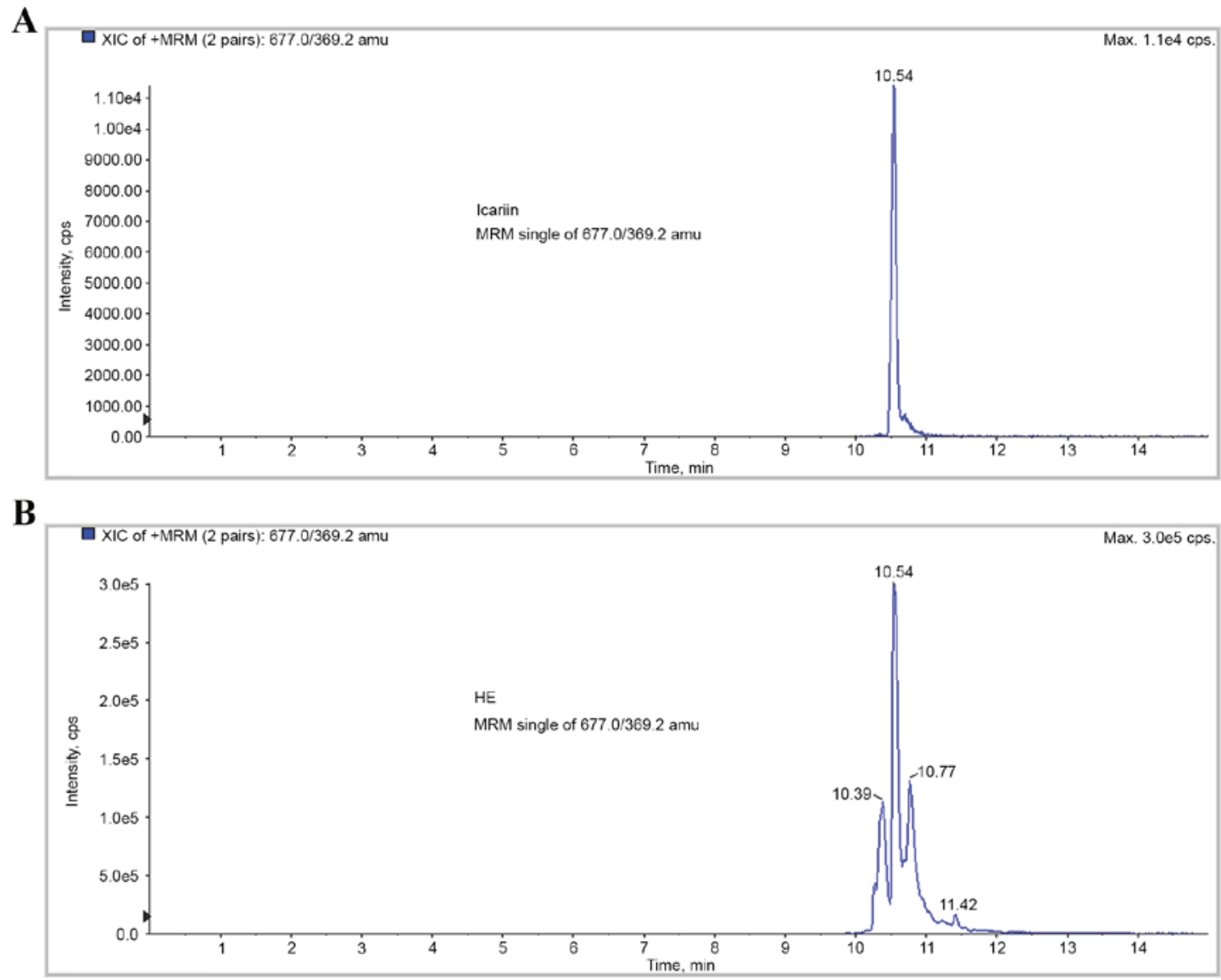

Figure 1. LC-MS/MS chromatograms of HE extract. (A) In MRM mode, icariin was used as reference standard of HE was represented at a retention time of 10.54 min. (B) LC-MS/MS analysis indicated that HE extract contained icariin as a representative compound of HE with the same retention time. LC-MS/MS, liquid chromatography-tandem mass spectrometry; HE, herbal Epimedium; MRM, multiple reactions monitoring.

Statistical analysis. Statistical analysis was performed using GraphPrism software, version 4.0.3 (GraphPad Software, Inc., La Jolla, CA, USA). Data from the MTT assay are presented as the mean and standard deviation, and were analyzed using SPSS, version 12.0 (SPSS, Inc., Chicago, IL, USA).

\section{Results}

Detection and quantification of HE using LC-MS/MS. To identify and confirm the compound of HE extract was analyzed using an LC-MS/MS method. Icariin was used as an indicative compound investigated in the positive ionization mode of LC-MS/MS. Quantification was performed using MRM mode at $\mathrm{m} / \mathrm{z} 677 \rightarrow 396.2$ for icariin and detected at a retention time of $10.54 \mathrm{~min} .10 \mathrm{mg} / \mathrm{ml} \mathrm{HE}$ extract containing $29.9 \mu \mathrm{g} / \mathrm{ml}$ icariin (Fig. 1).

$H E$ inhibits $m B M M S C$ proliferation. The effects of $\mathrm{HE}$ on the proliferation of $\mathrm{mBMMSCs}$ were determined from cell growth kinetics with the MTT assay measuring the metabolic activity of viable cells. Growth-arrested mBMMSCs, cultured in starvation medium for $24 \mathrm{~h}$ prior to the experiment, were incubated for 12,24 or $48 \mathrm{~h}$ with $\mathrm{HE}$. The results indicated that HE-treated cells exhibited reduced cell viability compared with untreated controls. As presented in Fig. 2, treatment with $\mathrm{HE}$ at concentrations up to $100 \mathrm{mg} / \mathrm{ml}$ for up to $48 \mathrm{~h}$ inhibited cell proliferation in a dose- and time-dependent manner to a maximum of $45.43 \pm 3.33 \%$ $(\mathrm{P}<0.001$; Fig. 2A).

Measurement of PCNA immunoreactivity in proliferating $m B M M S C s$ treated with $H E$. The antiproliferative effects of $\mathrm{HE}$ were further confirmed using PCNA, a protein that participates in DNA replication. In these experiments, cells grown in complete medium were treated with $\mathrm{HE}(100 \mathrm{mg} / \mathrm{ml}, 24 \mathrm{~h})$ in the presence or absence of SB202190 or PD98059, inhibitors of p38 and extracellular signal-related kinase $1 / 2$, respectively, and then incubated with the fluorescent DNA binding dye, PI, for nuclear staining (red) and with an antibody directed against PCNA (green). As expected, treatment with bFGF, an inducer of cell growth and proliferation, resulted in an increase in PCNA staining (Fig. 2B). In contrast, HE reduced the level of PCNA expression, and pretreatment with SB202190 and PD98059 further reduced the level of PCNA compared with cells treated with HE alone (Fig. 2B).

Effects of HE on apoptosis. MSCs exhibited a reduction in the number of live cells and increases in both apoptotic and dead cells (early or late apoptosis) at both 24 and $48 \mathrm{~h}$ after treatment with HE. The percentages of MSCs undergoing late apoptosis at 24 and $48 \mathrm{~h}$, as determined by annexin V-FITC/PI staining, were increased in HE-treated cells (71.93 and 67.03\% vs. $14.93 \%$, respectively), while the percentages of HE-treated MSCs undergoing early apoptosis were similar to that of 
A

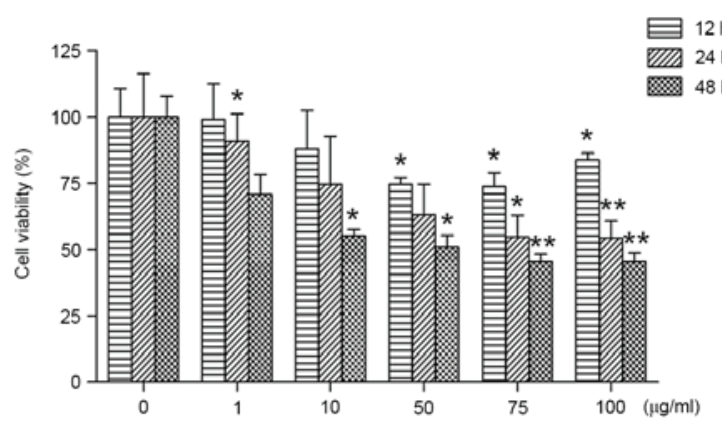

C
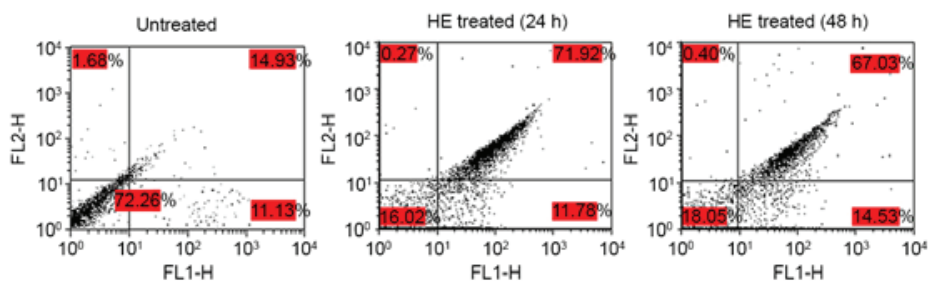

B
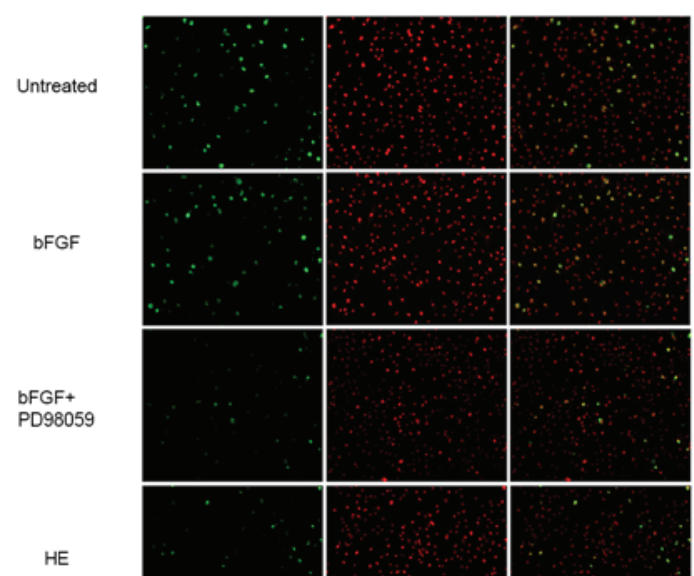

HE + PD98059
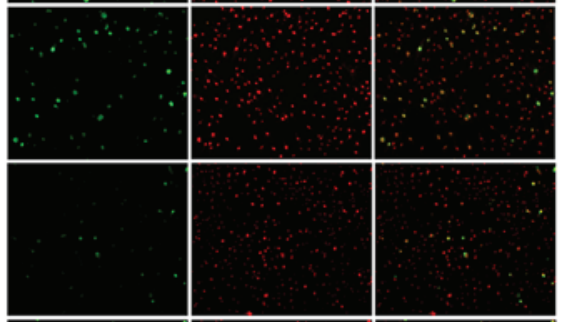

$\mathrm{HE}$
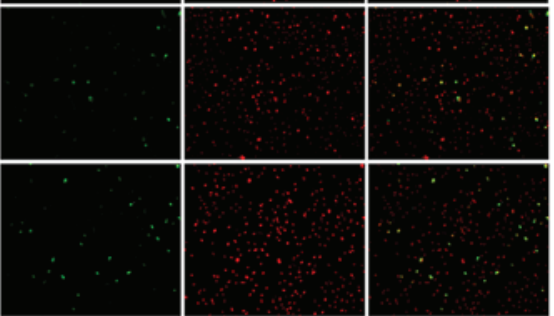
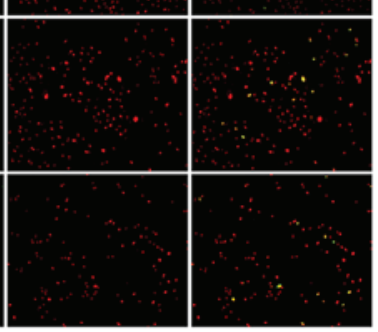

Figure 2. (A) Growth inhibitory effect of HE on mBMMSC proliferation. mBMMSCs were starved for $24 \mathrm{~h}$ and treated with HE as indicated for 12,24 or 48 h. Normal $(0 \mu \mathrm{g} / \mathrm{ml})$, PBS-treated cells. Each column represents the mean \pm standard deviation $(\mathrm{n}=3)$. ${ }^{*} \mathrm{P}<0.05,{ }^{* *} \mathrm{P}<0.01$ vs. normal value. (B) Effects of HE on PCNA immunoreactivity in mBMMSCs. mBMMSCs grown in complete medium were incubated in the presence or absence of either SB202190 (30 mM, 2 h) or PD98059 (30 mM, 2 h) prior to incubation with HE (100 mg/ml, $24 \mathrm{~h})$. Cells were then stained with PI for detection of nuclei (red) or with an anti-PCNA antibody (green). Overlay images of both stains are also presented. bFGF was used as a positive control. All images were obtained using magnification of $\mathrm{x} 20$ with an Olympus BX-61 fluorescence microscope. (C) HE induced mBMMSCs apoptosis. Apoptosis was measured by annexin V-FITC/PI staining and analyzed by flow cytometry. Horizontal and vertical axes represent labeling with annexin V-FITC and PI, respectively. Lower left, live cells; lower right, early apoptotic cells; upper left, necrotic cells; upper right, late apoptotic cells. HE, herbal Epimedium; mBMMSCs, mouse bone marrow mesenchymal stem cells; PCNA, proliferating cell nuclear antigen; PI, propidium iodide; bFGF, basic fibroblast growth factor; FITC, fluorescein isothiocyante.

untreated cells (11.78 and $14.3 \%$ vs. $11.13 \%$, respectively) (Fig. 2C).

An important feature of mBMMSCs is their ability to differentiate into osteoblasts, chondroblasts and adipocytes. To determine whether $\mathrm{HE}$ affects the osteogenic and adipogenic differentiation capacity of the cells, mBMMSCs were treated with $\mathrm{HE}$ at a concentration of $100 \mathrm{mg} / \mathrm{ml}$ for three weeks. Both Alizarin red and Von Kossa staining assays clearly indicated strong induction of differentiation of $\mathrm{mBMMSCs}$ to the osteogenic lineage by HE treatment (Fig. 3A and B). Adipose droplets, a representative marker of adipogenic induction of mBMMSCs, was not detected up to 3 weeks subsequent to $\mathrm{HE}$ treatment (Fig. 3C).

\section{Discussion}

HE has been widely used in the treatment of bone-associated diseases, including osteoporosis (14). However, the molecular mechanisms underlying the effects of HE remain to be fully elucidated. In the present study, the effects of HE on MSC differentiation into osteogenic lineage cells were investigated.

The results of cell viability assays indicated that HE inhibited cell proliferation of mBMMSCs in a dose-dependent manner. And this was confirmed through the examination of PCNA, a protein that participates in DNA replication. The results indicated that HE reduced the level of PCNA expression compared with that of untreated cells. With appropriate stimulation, adult stem cells proceed though the cell cycle to replace the stem cell population, and then give rise to a variety of differentiated cell types for tissue regeneration and homeostasis (18). By contrast, cell cycle or growth arrest can lead to tumor suppression and normal cell differentiation (19).

Apoptosis, which is programmed cell death, is a normal physiological process involved in embryonic development in addition to adult tissue homeostasis. Undifferentiated human MSCs (hMSCs) are resistant to apoptosis. By contrast, hMSCs during differentiation exhibit increased apoptosis regulated by members of the BCL-2 family (20). The present study demonstrated that HE could additionally induce apoptosis in MSCs; the percentage of MSCs undergoing apoptosis was markedly increased in HE-treated cells. As cell cycle arrest or apoptosis can trigger cell differentiation and gene expression involved in differentiation (21), it is suggested that HE may induce differentiation instead of promoting the cell cycle and proliferation of $\mathrm{mBMMSC}$.

HE induced mBMMSCs to undergo differentiation into osteogenic lineage cells, however not into adipogenic lineage cells, suggesting that $\mathrm{HE}$ is a potential candidate for promoting MSC into osteogenic differentiation to improve metabolic bone diseases including osteoporosis. 
A

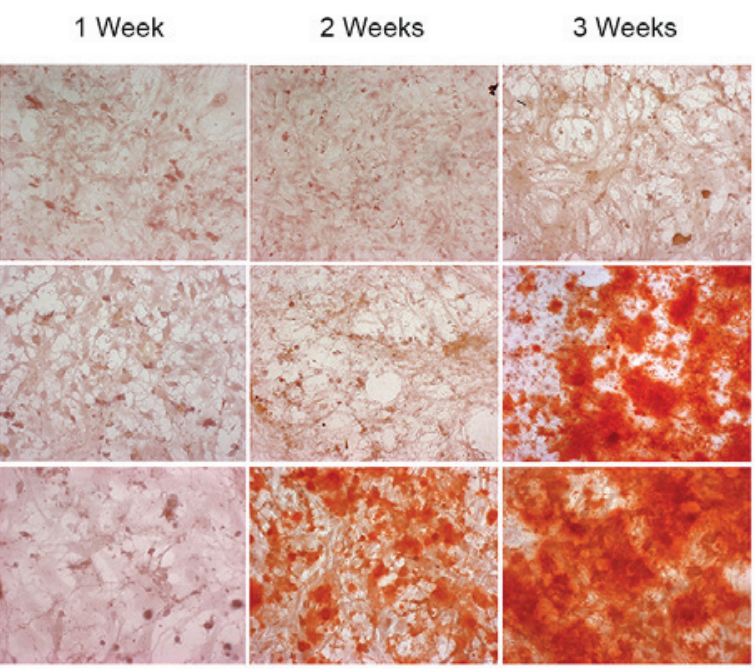

B

HE

Osteogenic

induction medium

Osteogenic

induction medium

1 Week

2 Weeks

3 Weeks
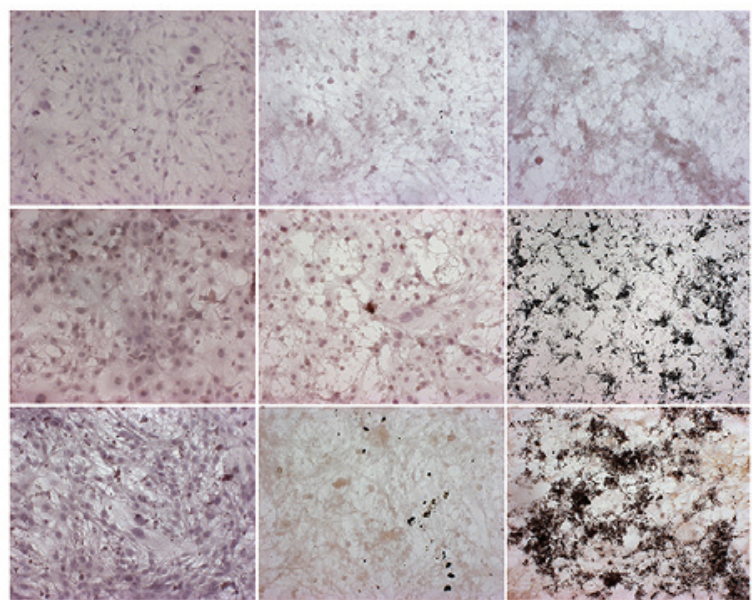

C

1 Week

2 Weeks

3 Weeks

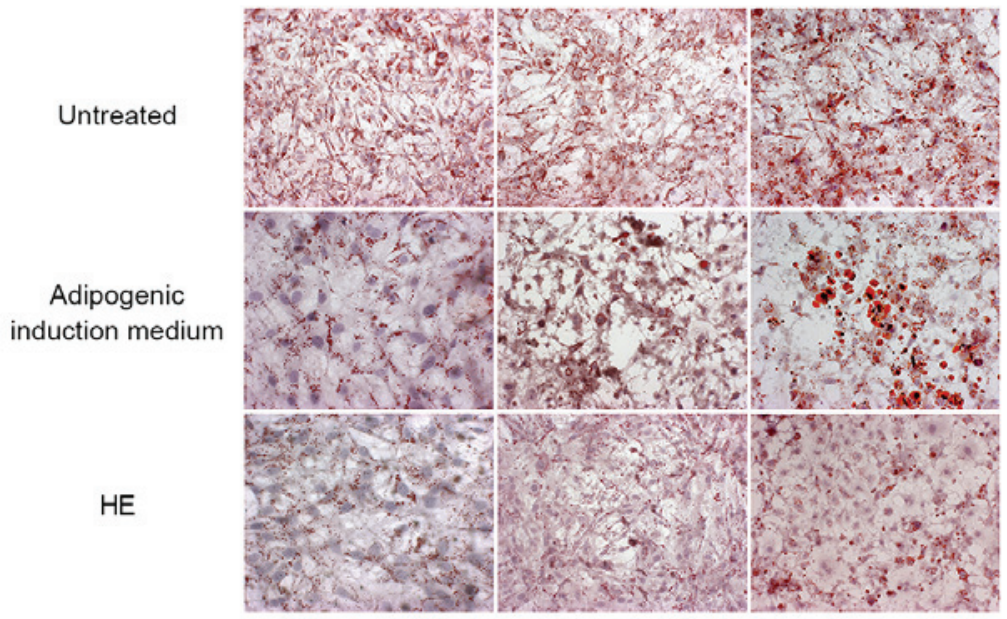

Figure 3. In vitro osteogenic and adipogenic differentiation of mBMMSCs induced by HE treatment. Cells were treated with HE or induction medium for 1,2 or 3 weeks. Original magnification, x20. (A) For detection of nodule-like structures, osteogenic cultures were stained with Alizarin red. (B) For detection of calcium-phosphate deposits, osteogenic cultures were subjected to Von Kossa staining. (C) For detection of adipose droplets, adipogenic cultures were stained with Oil red O. HE, herbal Epimedium.

Although further studies are required to determine the signaling mechanism by which HE regulates mBMMSC growth and differentiation, the current study provides information on how limitations of clinical use of stem cell therapy such as transplantation, in vitro induction and expansion of differentiated cells, and endogenous induction of stem cell differentiation into specific cell type lineages, might be overcome. 


\section{References}

1. Gennari L, Rotatori S, Bianciardi S, Gonnelli S, Nuti R and Merlotti D: Appropriate models for novel osteoporosis drug discovery and future perspectives. Expert Opin Drug Discov 10: $1201-1216,2015$

2. Sambrook P and Cooper C: Osteoporosis. Lancet 17: 2010-2018, 2006.

3. Arceo-Mendoza RM and Camacho P: Prediction of fracture risk in patients with osteoporosis: A brief review. Womens Health (Lond Engl) 11: 477-482, 2015.

4. Iñiguez-Ariza NM and Clarke BL: Bone biology, signaling pathways, and therapeutic targets for osteoporosis. Maturitas 82 245-255, 2015.

5. Mikami Y, Matsumoto T, Kano K, Toriumi T, Somei M, Honda MJ and Komiyama K: Current status of drug therapies for osteoporosis and the search for stem cells adapted for bone regenerative medicine. Anat Sci Int 89: 1-10, 2014.

6. Vitale AM, Wolvetang E and Mackay-Sim A: Induced pluripotent stem cells: A new technology to study human diseases. Int J Biochem Cell Biol 43: 843-846, 2011.

7. Tögel $\mathrm{F}$ and Westenfelder C: Adult bone marrow-derived stem cells for organ regeneration and repair. Dev Dyn 236: 3321-3331, 2007.

8. Hentze H, Graichen R and Colman A: Cell therapy and the safety of embryonic stem cell-derived grafts. Trends Biotechnol 25: 24-32, 2007.

9. Chamberlain G, Fox J, Ashton B and Middleton J: Concise review: Mesenchymal stem cells: Their phenotype, differentiation capacity, immunological features, and potential for homing. Stem Cells 25: 2739-2749, 2007.

10. Ozawa K, Sato K, Oh I, Ozaki K, Uchibori R, Obara Y, Kikuchi Y, Ito T, Okada T, Urabe M, et al: Cell and gene therapy using mesenchymal stem cells (MSCs). J Autoimmun 30: 121-127, 2008.

11. Jethva R, Otsuru S, Dominici M and Horwitz EM: Cell therapy for disorders of bone. Cytotherapy 11: 3-17, 2009.
12. Van Damme A, Vanden Driessche T, Collen D and Chuah MK: Bone marrow stromal cells as targets for gene therapy. Curr Gene Ther 2: 195-209, 2002.

13. Yan FF, Liu Y, Liu YF and Zhao YX: Herba epimedii water extract elevates estrogen level and improves lipid metabolism in postmenopausal women. Phytother Res 22: 1224-1228, 2008.

14. Sze SC, Tong Y, Ng TB, Cheng CL and Cheung HP: Herba epimedii: Anti-oxidative properties and its medical implications. Molecules 15: 7861-7870, 2010.

15. Chen WF, Mok SK, Wang XL, Lai KH, Lai WP, Luk HK, Leung PC, Yao XS and Wong MS: Total flavonoid action of the Herba epimedii extract suppresses urinary calcium excretion and improves bone properties in ovariectomised mice. Br J Nutr 105: 180-189, 2011.

16. Nadri $\mathrm{S}$ and Soleimani M: Isolation murine mesenchymal stem cells by positive selection. In Vitro Cell Dev Biol Anim 43: 276-282, 2007.

17. Eslaminejad MB and Nadri S: Murine mesenchymal stem cell isolated and expanded in low and high density culture system: Surface antigen expression and osteogenic culture mineralization. In Vitro Cell Dev Biol Anim 45: 451-459, 2009.

18. Bonab MM, Alimoghaddam K, Talebian F, Ghaffari SH, Ghavamzadeh A and Nikbin B: Aging of mesenchymal stem cells in vitro. BMC Cell Biol 7: 14, 2006.

19. Yee AS, Paulson EK, McDevitt MA, Rieger-Christ K, Summerhayes I, Berasi SP, Kim J, Huang CY and Zhang X: The HBP1 transcriptional repressor and the p38 MAP kinase: Unlikely partners in G1 regulation and tumor suppression. Gene 336: 1-13, 2004.

20. Oliver L, Hue E, Rossignol J, Bougras G, Hulin P, Naveilhan P, Heymann D, Lescaudron L and Vallette FM: Distinct roles of $\mathrm{Bcl}-2$ and $\mathrm{Bcl}-\mathrm{Xl}$ in the apoptosis of human bone marrow mesenchymal stem cells during differentiation. PLoS One 6: e19820, 2011.

21. Napolitano MA, Cipollaro M, Cascino A, Melone MA, Giordano A and Galderisi U: Brg1 chromatin remodeling factor is involved in cell growth arrest, apoptosis and senescence of rat mesenchymal stem cells. J Cell Sci 15: 2904-2911, 2007. 